\title{
Delayed health care seeking is high among patients presenting with sexually transmitted infections in HIV hotspot areas, Gambella town, Ethiopia
}

This article was published in the following Dove Press journal: HIVIAIDS - Research and Palliative Care

\author{
Mache Tsadik' \\ Lul Lam $^{2}$ \\ Zinabu Hadush' \\ 'School of Public Health, College of \\ Health Science, Mekelle University, \\ Tigray, Ethiopia; ${ }^{2}$ Department of Disease \\ Prevention and Control, Gambella \\ Regional Health Bureau, Ethiopia
}

Background: Delayed health care seeking is one of the major impediments to successfully prevent and control sexually transmitted infections (STIs) including HIV. Gambella is one of the HIV hot spot areas and the most HIV prevalent region in the country. Considering the empirical knowledge of the link between STIs and HIV, gathering information on healthseeking behavior and the associated factors among STI patients is helpful to design interventions that enhance early seeking and treatment adherence.

Methodology: A facility-based cross-sectional study was employed to collect data from 424 STI patients from February 15 to April 15, 2017, using a face-to-face interview. A consecutive sampling method was used until the allocated sample for each facility was fulfilled. A multivariate logistic regression analysis was used to identify factors associated with health-seeking behavior.

Results: The proportion of delayed health care seeking among patients treated for STIs was $56.8 \%$. Knowledge, number of sexual partners, and perception variables were found significantly associated with early seeking behavior in multivariate logistic regression: patients who had better knowledge of STIs (AOR $=1.74,95 \% \mathrm{CI}=1.10,2.73$ ), had single sexual partner (AOR $=1.83$, $95 \% \mathrm{CI}=1.19,2.78$ ), those who perceived stigma for STIs ( $\mathrm{AOR}=0.52,95 \% \mathrm{CI}=0.34,0.79$ ), and perceived severity of STIs (AOR $=1.97,95 \% \mathrm{CI}=1.18,3.29$ ).

Conclusion: This study reported a high proportion of delayed health care seeking. This may challenge the prevention and control effort and alarms the potential threat to the spread of $\mathrm{STI} / \mathrm{HIV}$ in the region. Provision of intensive health education is crucial to improve awareness and to avoid risk behaviors and negative perceptions.

Keywords: health, seeking, behavior, sexually, transmitted, infection, Gambella

\section{Introduction}

Sexually transmitted infections (STIs) are a major public health concern in developing countries. ${ }^{1}$ In sub-Saharan Africa, STIs and their associated complications account for a substantial proportion of outpatient care visits ranking among the top five leading causes of health care seeking. ${ }^{2-4}$ Health care seeking is a usual habit of the community that happened as a result of the interaction and balance between health needs, health resources, and socioeconomic, cultural, political, and national or international contextual factors. ${ }^{5}$

The problem related to health care-seeking behavior is fundamental to all society and the consumption of health service is complex in the developing countries. ${ }^{6}$ Health-seeking behavior affects people's actions when they suspect an
Correspondence: Mache Tsadik School of Public Health, College of Health Science, Mekelle University, Tigray, Ethiopia Tel +25I 91474 384I

Email adhana2008@gmail.com 
infection. People who experienced a symptom of STI delay to seek care timely or do not seek care despite the available service. Consequently, delayed treatment or untreated infection can lead to pelvic inflammatory disease, ectopic pregnancy, infertility, cervical cancer, fetal loss, a health problem of newborn, and increased risk of HIV infection. ${ }^{4}$

Reports showed that individuals with one or more of STI symptoms often visit health care facilities too late. The timing of the health care seeking behavior among individuals is often influenced by socio-demographic, behavioral, perception, and knowledge of STIs. Besides, access to health care and cultural norms of society matters the time for health care seeking among STI patients. STI treatment and care are often embarrassing and disgraceful. ${ }^{7}$ As a consequence, patients may prefer to have self-medication accessed from private facilities with limited counseling of antibiotic drug use that potentially lead to drug resistance. ${ }^{8}$

In Ethiopia, the presence of the symptom triggers individuals to seek care for STIs ${ }^{9}$ and it is also the commonest reason for visiting health care. In contrast, some symptoms can cause loss of innocence and shame which in turn cause a delay in health care seeking followed by serious complications. ${ }^{10}$

In previous studies, inconsistent findings were reported regarding the prevalence of delay in health care seeking. For instance, the delay in health care seeking of patients presented with STIs was $23.1 \%$ in Durban, South Africa. ${ }^{11}$ In Laos, delayed health care seeking for STIs was $42 \%{ }^{12}$ In a study conducted in Ghana, $64 \%$ of the patients delayed seeking treatment for STIs. ${ }^{13}$ Other studies conducted in Uganda and Ethiopia reported 58\% and 67\% of delayed care seeking among STI patients, respectively. ${ }^{14,15}$

Health care-seeking behavior is often influenced by socio-demographic, behavioral, and health system factors. ${ }^{16}$ Utilization of health care often depends on socio-demographic factors, social structures, cultural beliefs and practices, economic and political systems, environmental conditions, and the disease pattern and health care system itself. ${ }^{17}$ Unfriendly health service, lack of privacy, a culture, and perceived norms cause variation in individual preference to seeking health care. ${ }^{18}$ Level of education, being HIV negative, had a friend who did not seek treatment, misconceptions about the cause of STIs, perceived the severity of STIs and no condom use were reported as factors for delay in health care seeking. ${ }^{11,13}$ Studies also revealed the association of health care-seeking behavior with limited access to health services, negative attitude of health workers, socio-cultural, and gender issues. ${ }^{19,20}$ A review study also identified confidentiality, cost, and stigma as barriers to making a decision to seek care. ${ }^{21}$

Ethiopia has adopted the National guideline for syndromic management of STIs and identified the STI prevention and control as one of the strategies to prevent and control HIV/AIDS. In this country, particularly in the Gambella region, various interventions such as mass male circumcision, improved access to health care and HIV screening programs have been undertaken to reduce the burden of STIs including HIV. Despite this, the prevalence of STIs and HIV remained high in Gambella region which is labeled as high HIV hot spot area. In fact, early health care utilization and adherence to effective treatment can reduce morbidity, disability, and mortality resulting from STIs ${ }^{22}$ and in contrast, a delay in health care seeking prolongs the period of infectiousness and thereby increase the incidence of the infection of STIs including HIV. ${ }^{23}$ Considering this fact, little is known about the timing (being early or late) of health care seeking among patients presented with STIs in the health facilities of Gambella town. Thus, this study aimed to assess the magnitude and factors associated with health care seeking among patients attending health facilities for STI care in Gambella town.

\section{Methods and materials Study design and population}

The study was conducted in public and private health facilities of Gambella town, located southwest of Addis Ababa, Ethiopia. A facility-based cross-sectional study was employed to collect data on health-seeking behavior of STI patients attending STI care in selected health facilities of Gambella town from February 15 to April 15, 2017. Patients who were syndromically diagnosed as having STIs during the study period were considered as the eligible study population.

\section{Sample size and procedure}

A double population proportion formula was employed to determine sample size for the determinants of health-seeking behavior among STI patients using the following assumptions: $41.79 \%$ of the married individuals with early seeking behavior, ${ }^{24} 80 \%$ power with $95 \%$ Confidence level which gave us a final sample size of 435 . It estimated the difference between two populations. 
Initially, health facilities were stratified into public and private and then all the public health facilities (one hospital and one health center) were purposively selected. Among the private health facilities, eight $(50 \%)$ were selected using the lottery method. Study participants were allocated to the selected health facilities based on equal population proportion to size.

\section{Data collection tool and procedure}

The tool was developed by reviewing different kinds of literature ${ }^{5,11,13,14,19,20}$ and existing guidelines ${ }^{9}$ and finally modified into the context of the study. The tool consisted of socio-demographic, behavioral, psychological, and health system factors as well as knowledge of STIs. A pretest was made on $5 \%$ of the study population in a health facility not selected for the actual study 1 week before the actual data collection period. The tool was initially developed in English and translated into Amharic as the majority of the population speaks Amharic as a common language. Data collectors were nurses who trained for 2 days in regard to research objective, confidentiality, interviewing techniques and ethical issues. Initially, patients were verbally consented and those syndromically diagnosed as having STIs in the selected health facilities were consecutively interviewed using interviewer-administered questionnaire until the required sample size was fulfilled. Eligible study participants from the Outpatient Department were linked to the data collectors, and the interview was conducted in a private room after patients received routine care in the facility.

\section{Variables and measurements}

The outcome variable in this study was health care seeking for STIs. It had two response categories: 1) Early seeking behavior refers to patients who seek care within 7 days of the onset of the symptoms and coded as "1". and (2) Delayed seeking behavior refers to patients who seek care after 7 days of the onset of STI symptoms and coded as "0". The measurement for the outcome variable was adopted from previous studies. ${ }^{12,25,26}$ Data regarding reasons for delayed health care were collected by asking study participants "when did you start to have the most recent symptoms?" followed by "why you did not come early" for those who had one or more of the STI symptoms more than a week,

Patients' knowledge on STIs was measured using 20 items in terms of transmission, symptoms, prevention, and complications with a response category of " $1=$ Yes", " $2=$ No", and
" 3 = I don't know". A mean score was used to determine the knowledge status of respondents on STIs. Respondents who scored above the mean were categorized as having better knowledge and those who scored equal to or below mean were categorized as having poorer knowledge. Finally, the latent variable "STI knowledge score" was used for further analysis in regressions.

\section{Data analysis}

The data were entered into EPI-INFO Version 7.01 for storing and cleaning and exported to SPSS version 20 for analysis. Descriptive statistics of frequency and percentage distribution of the variables was generated. The independent variables were assessed for association with the dependent variable at a $p$-value of 0.25 in bivariate analysis. Those variables found statistically significant at a $p$ value less than 0.25 were considered for further analysis in multivariable regression. The adjusted odds ratio was reported at $95 \%$ confidence interval whereas statistically significant variables were declared at $p$-value $<0.05$

Ethical approval and clearance were obtained from the Ethical Review Committee of Mekelle University, College of Health Sciences. Permission was also obtained from Gambella Regional Health Bureau, Gambella town administration health office and head from select health facilities for cooperation between patients and data collectors. Verbal informed consent was acceptable and approved by the Ethical Review Committee of Mekelle University. Information regarding study participants under the age of 18 years was collected without parents or guardians consent as STI care needs privacy and confidentiality and this was accepted and approved by the ethical review committee of Mekelle University. Patients were allowed to ask questions before they provide a verbal consent, and a clear explanation was given to them about the aim of the study and confidentiality. Patients were well informed that the information obtained from the respondents will not be used for other purposes other than the study aim.

\section{Results}

\section{Sociodemographic characteristics}

Among the total of 435 STI patients, 424 (97.5\%) agreed to participate in the study and completed the questionnaire correctly after open recruitment of patients in the selected health facilities. The mean age of the respondents was 25.1 \pm 6.551 years with a range of $15-44$ years. The majority of $235(55.4 \%)$ of the participants were in the age category between 15 and 24 years. 
Among the respondents, nearly 50\% were males; the dominant Ethnic group was Nuer contributing about 30\%; about $54.5 \%$ of the respondents were unmarried; about $73.1 \%$ of the respondents were protestants in religion and about $63 \%$ of the respondents attained secondary school and above. Nearly $94 \%$ of the respondents reside in an urban setting (Table 1).

\section{Knowledge of STIs}

This study assessed four aspects of STIs knowledge including transmission, symptoms, prevention, and complications which consists of 20 item questions. The mean score of knowledge was 10.21 with SD of 4.54. Nearly, $43 \%$ of the respondents scored above the mean (had better knowledge) with the Cronbach`s Alpha score of 0.77 .

Twenty knowledge items were loaded to principal component factor analysis fixed factor (4) using varimax rotation: transmission, symptoms, and prevention and complications questions. The number of items loaded to the components of knowledge by 0.3 and above was considered under each aspect. Accordingly, the number of items loaded to transmission, symptoms, prevention, and complications were 5, 7, 3,

Table I The socio-demographic characteristics of sexually transmitted infections (STI) patients in Gambella town, April 2017

\begin{tabular}{|l|l|l|l|}
\hline Variable & Response & Frequency & $\%$ \\
\hline Sex & Male & 217 & 51.8 \\
& Female & 207 & 48.2 \\
\hline Age & $15-24$ & 235 & 55.4 \\
& $25-34$ & 146 & 34.5 \\
& $\geq 35$ & 43 & 10.1 \\
\hline \multirow{2}{*}{ Ethnicity } & Anywaa & 104 & 24.5 \\
& Nuer & 129 & 30.4 \\
& Non-Anywaa/Nuer & 191 & 45.1 \\
\hline Marital status & Unmarried & 231 & 54.5 \\
& Married & 166 & 39.2 \\
& Separated/widowed & 27 & 6.3 \\
\hline Religion & Protestant & 310 & 73.1 \\
& Orthodox & 72 & 17.0 \\
& Muslim & 42 & 9.9 \\
\hline \multirow{2}{*}{ Educational level } & Illiterate & 82 & 19.3 \\
& Primary & 75 & 17.7 \\
& Secondary and above & 267 & 63.0 \\
\hline Residence & Urban & 397 & 93.6 \\
& Rural & 27 & 6.4 \\
\hline
\end{tabular}

Note: Non-Anywaa/Nuer: Mejeng, Tigre, Amhara, Gurage, Oromo, Opo, Komo and Kambata. and 5, respectively. Collectively the components explained $29.5 \%$ of the variance in Knowledge about STI (Table 2).

\section{Patient's risky sexual behavior}

Majority of respondents ( $86 \%$ ) knew that the use of condom protects from STIs. However, $64 \%$ of the respondents did not use a condom at the time of sexual intercourse with their non-regular sexual partners. About $40 \%$ of the respondents ever used a condom to prevent pregnancy and only $21.7 \%$ of the respondents used a condom to prevent STI. Nearly one-third of male respondents had sexual intercourse with female sex workers. The mean age at first sexual intercourse among respondents was about $16 \%$ (Table 3 ).

\section{Reasons for delay in health care seeking}

The major reasons reported for delayed health care seeking among patients visiting health facility for STIs treatment were being gone to pharmacies, perception of judgmental health workers, cost of services, and feeling of shame which account for about two-third of the patients who reported delayed health care (Figure 1). Feeling guilty, seeking holy water, use of traditional medicine, and not available medicine for STIs contribute for the rest of the reasons for delay in seeking health care for STIs.

\section{Reasons for not using a condom}

The major reason for not using condom among the respondents was due to lack of availability of condom followed by shame and diminished sexual pleasure (Figure 2).

\section{Presented syndromes among study participants}

Vaginal discharge syndrome was the highest accounted for $30.7 \%$ followed by urethral discharge $(28.5 \%)$ and genital ulcer (27.1\%) (Figure3).

Table 2 Aspects of sexually transmitted infections (STI) knowledge among patients visiting health facility in Gambella town, April 2017

\begin{tabular}{|l|l|l|l|}
\hline Aspect of STI knowledge & $\begin{array}{l}\text { Mean } \\
\text { score }\end{array}$ & SD & $\begin{array}{l}\text { Cronbach's } \\
\text { alpha score }\end{array}$ \\
\hline Knowledge of transmission & $3.25^{*}$ & 1370 & 0.70 \\
Knowledge of symptoms & 3.13 & $224 \mathrm{I}$ & 0.775 \\
Knowledge of prevention & 2.28 & 1.103 & 0.840 \\
Knowledge of complications & 1.55 & 1.80 & 0.780 \\
Overall knowledge of STI & 10.21 & $4.54 \mathrm{I}$ & 0.77 \\
\hline
\end{tabular}


Table 3 Behavioral, perception and cultural-related factors of respondents in Gambella town, April 2017

\begin{tabular}{|c|c|c|c|}
\hline Variable & Response & Frequency $(n=424)$ & Percentage (\%) \\
\hline \multirow[t]{2}{*}{ Ever use of a condom } & Yes & 129 & 35.2 \\
\hline & No & 237 & 64.8 \\
\hline \multirow[t]{2}{*}{ Age at Ist sexual intercourse } & $<15$ years & 75 & 17.7 \\
\hline & $\geq 15$ years & 349 & 82.3 \\
\hline \multirow[t]{2}{*}{ No of sexual partner the last 12 months } & Single & 177 & 41.7 \\
\hline & Two or more partners & 247 & 58.3 \\
\hline \multirow[t]{2}{*}{ Fear of stigma for STls } & Yes & 184 & 43.4 \\
\hline & No & 240 & 56.6 \\
\hline \multirow[t]{2}{*}{ Sex with FSW } & Yes & 74 & 34.1 \\
\hline & No & 143 & 65.9 \\
\hline
\end{tabular}

Abbreviation: STI, sexually transmitted infections; FSW, female sex workers.

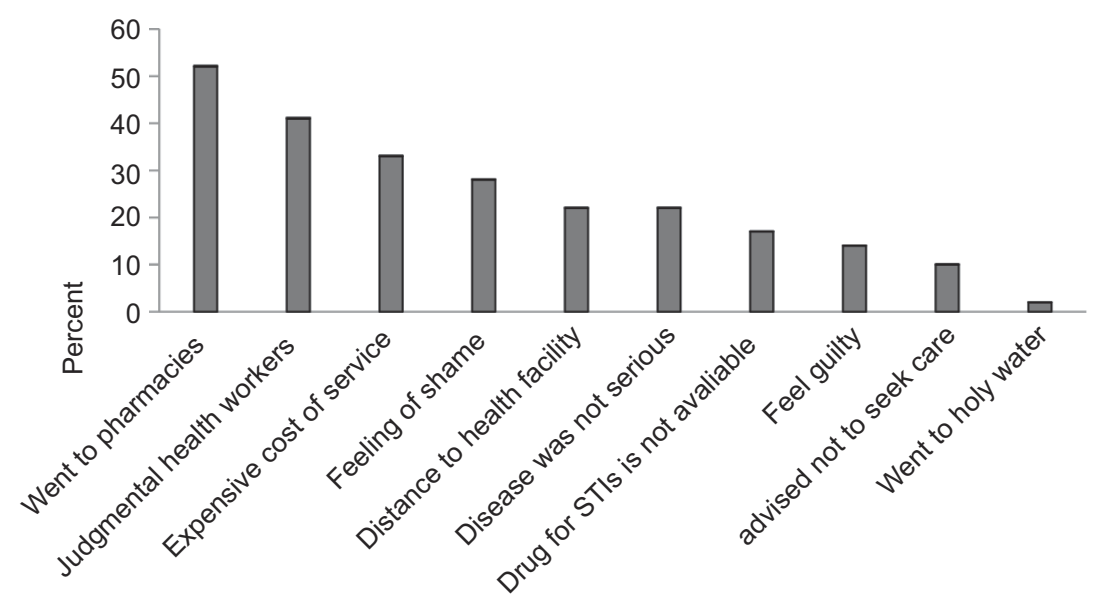

Figure I Reason for delay in health care seeking among sexually transmitted infections (STI) patients in Gambella town, April 2017.

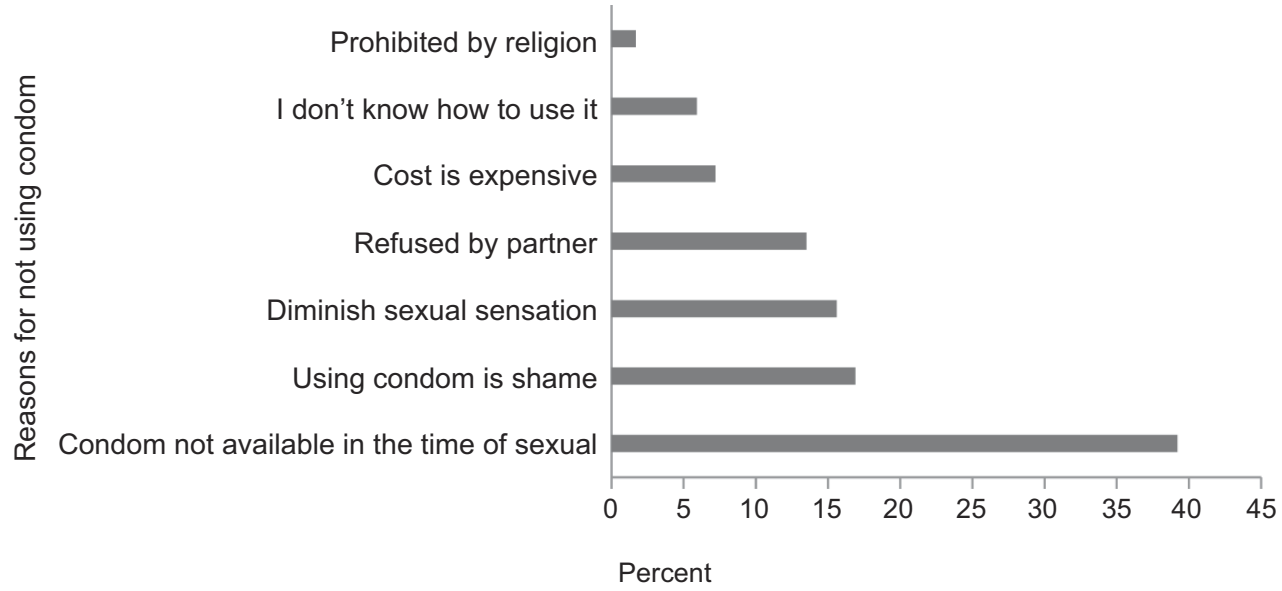

Figure 2 Reasons for not using condom reported by respondents in Gambella town, April 2017. 


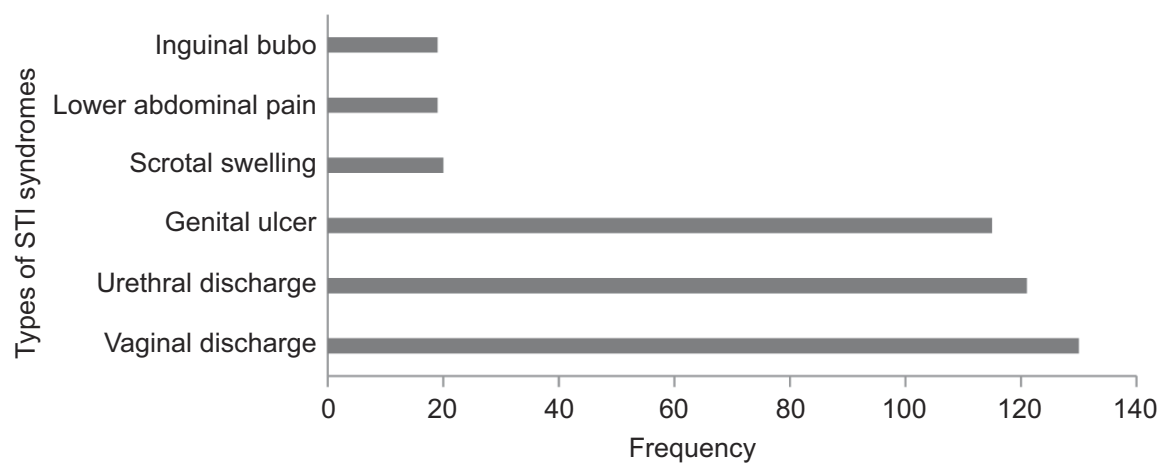

Figure 3 Distribution of sexually transmitted infections (STI) syndromes among respondents in Gambella town, April 2017.

\section{Health-seeking behavior of respondents}

Lower than half $(43.2 \%)$ of study participants seek health care early within 7 days. The mean time of health seeking from the onset of symptom to the first visit to the health facility was 10 days. Some of the reasons reported for delay of health-seeking behavior by respondents were: initial use of drugs from pharmacies and drug vendors, cost of service, fear of stigma from care providers, lack of access to treatment and considering that the disease is not serious.

\section{Factors associated with health-seeking behavior}

Binary logistic regression analysis was applied to assess factors associated with health care seeking. To reduce the excessive number of variables and instability of the model, only variables with $P$-value $<0.25$ in the bivariate analysis were considered for inclusion in the multivariate analysis. Significance in the final model was considered at a $p$-value less than 0.05 .

According to the above inclusion criteria, the following variables were considered in the final model: sex and marital status among the socio-demographic variables; knowledge of STIs; the number of sexual partners from sexual behaviorrelated factors; perceived severity and fear of stigma for STIs among perception-related questions (Table 4).

Adjusting for the effect of other variables in the model, the odds of early seeking behavior for STIs were 1.74 times higher among patients who had better knowledge of STIs compared to those with poorer knowledge (AOR $=1.74,95 \% \mathrm{CI}=1.10,2.73)$. Patients with a single partner

Table 4 Bivariate and multivariate analysis of socio-demographic, knowledge, behavioral, and perception factors of STI patients in Gambella town, April 2017

\begin{tabular}{|c|c|c|c|c|c|}
\hline \multirow[t]{2}{*}{ Variable } & \multirow[t]{2}{*}{ Response } & \multicolumn{2}{|c|}{ Health-seeking behavior } & \multirow[t]{2}{*}{ COR $(95 \% \mathrm{Cl})$} & \multirow[t]{2}{*}{ AOR $(95 \% \mathrm{Cl})$} \\
\hline & & Early & Late & & \\
\hline \multirow[t]{2}{*}{ Sex } & Male & $84(38.7 \%)$ & $133(61.3 \%)$ & 1 & 1 \\
\hline & Female & 99 (47.8\%) & $108(52.2 \%)$ & $1.45(0.99,2.14)^{*}$ & $0.78(0.51,1.19)$ \\
\hline \multirow[t]{2}{*}{ Marital status } & Unmarried & $109(47.2 \%)$ & $122(52.8 \%)$ & $\mathrm{I}$ & 1 \\
\hline & Married & $74(38.3 \%)$ & $119(61.7 \%)$ & $0.70(0.97,2.12 *$ & $1.39(0.93,2.11)$ \\
\hline \multirow[t]{2}{*}{ Knowledge of STls } & Better & $132(72.1 \%)$ & |3| (54.4\%) & $2.17(1.01,1.66)^{*}$ & $1.74(1.10,2.73)^{* *}$ \\
\hline & Poorer & 51 (27.9\%) & 110 (45.6\%) & 1 & 1 \\
\hline \multirow[t]{2}{*}{ No of sexual partners } & Single partner & 95 (5I.9\%) & $82(34.0 \%)$ & $2.09(1.4 \mathrm{I}, 3.10)^{*}$ & $\mathrm{I} .83(\mathrm{I} .20,2.79)^{* *}$ \\
\hline & Two or more & $88(48.1 \%)$ & 159 (66.0\%) & 1 & I \\
\hline \multirow[t]{2}{*}{ Fear of stigma } & Yes & $65(35.5 \%)$ & 119 (49.4\%) & $0.56(0.38,0.84)^{*}$ & $0.52(0.34,0.79)^{* *}$ \\
\hline & No & $118(64.5 \%)$ & $122(50.6 \%)$ & 1 & I \\
\hline \multirow[t]{3}{*}{ Perceived severity } & Not serious & $101(55.2 \%)$ & $157(65.1 \%)$ & 1 & I \\
\hline & Neutral & $33(18.0 \%)$ & 44 (18.3\%) & $1.16(0.69,1.95)^{*}$ & $1.45(0.23,2.58)$ \\
\hline & Very serious & $49(26.8 \%)$ & $40(16.6 \%)$ & $1.90(1.17,3.09)^{*}$ & $1.97(1.18,3.29)^{* *}$ \\
\hline
\end{tabular}

Notes: *Significant variables $(P$-value $<0.25)$ in the bivariate logistic regression analysis. $* *$ Significant variables $(P$-value $<0.05)$ in multivariate logistic regression analysis. Abbreviations: STI, sexually transmitted infections; COR, crude odds ratio; AOR, adjusted odds ratio. 
were more likely to seek health care early compared to those who had multiple sexual partners (AOR $=1.83,95 \%$ CI $=1.19,2.78$ ). The odds of early health care seeking were 0.52 times lower among patients with fear of stigma for having STI as compared to their counterparties. (AOR $=0.52,95 \%$ CI $=0.34,0.79$ ). STI patients who perceived the illness as serious were nearly two times higher in seeking care compared to those who perceived no or less serious (AOR $=1.97,95 \% \mathrm{CI}=1.18,3.29)$ (Table 4).

\section{Discussion}

The study attempted to assess health care seeking and factors associated with STIs in Gambella Town. About $43 \%$ of the patients sought health care within 7 days. In this study, Knowledge, number of sexual partners, and perception-related variables were found significant predictors of early seeking behavior. Socio-demographic variables were not found to be significant predictors of healthseeking behavior in this study.

In the current study, more than half of the study participants seek care after the seventh day of onset of symptoms. The proportion of delayed health care seeking conducted in Addis Ababa and Uganda was similar to the current study. ${ }^{27,28}$ This implies that the majority of the patients practiced delayed health care seeking which leads to potential complications and highlighted the potential risk to the spread of STIs including HIV. On the other hand, the proportion of health care seeking conducted in Laos was higher than the current study. ${ }^{12}$ This variation might be related to the differences in culture, awareness, population under study, and access to health care. ${ }^{24,27,29}$ Overall, the higher proportion of delayed health care seeking for STIs may suggest the increased duration of infectiousness which is one of the factors that increase the STI dissemination and has a profound impact on the health of individuals related to infertility, ectopic pregnancy, cervical cancer, and increased risk of acquiring HIV. ${ }^{23,30}$

The most common reason for the delay in health care seeking in this study was self-medication (went to pharmacies) without the health care providers' prescription. Often, patients took medication for STIs until the symptoms subsided. ${ }^{31}$ This might result in drug resistance, development of complications and increased spread of the infection. The health system issues such as the providers' judgmental approach and cost of care are also among the reasons for the delay in health care seeking in this study similar to the previous study. ${ }^{13}$ Lack of friendly services discourages STI patients to seek care early and subsequently resulted in adverse health effects.

The social norms related to sexual practice or behavior vary in different population, subgroups and individual difference. Often, STIs are linked with stigma and shame which hinders the health-seeking behavior of patients. ${ }^{32}$ The individual level of awareness and perceived severity of the illness matters the health-seeking behavior of STI patients. In this study, patients' knowledge of STIs, behavior, and perception related factors were found statistically significant with the health-seeking behavior of patients presented with STIs.

The odds of early health care seeking for STI treatment were more likely among respondents who had better knowledge of STIs compared to their counterparties. This finding is consistent with the study conducted in Addis Ababa and southwest Ethiopia. ${ }^{27,33}$ This indicates that those who had better knowledge of STIs plays a role in reducing the burden of the disease by shortening the duration of infectiousness and spread through early health care seeking. Closing the knowledge gap regarding STIs through education and counseling is a strategy to avoid the delay in health care seeking and prevent the development of complications from STIs. ${ }^{34}$

Patients with single partner were more likely to seek health care early than those with multiple partners in this study. This is consistent with the study conducted in Gondar Town. ${ }^{35}$ The possible explanation could be those with a single partner are often married or in a union so that they worry about their health as well as the health of their partner. Besides, fear of complications and being committing risky sexual behavior may trigger them to seek care early. ${ }^{36}$ The probability of STI transmission increases with time if patients with STIs are not treated early,

Participants who reported fear of stigma for being exposed for STIs were less likely to seek health care early than their counterparties. This finding is consistent with the studies done in Pakistan, Nkomazi East, and rural Ethiopia. ${ }^{19,27,33}$ The stigma around STIs may still provide a barrier to timely health care seeking. For instance, patients presented with STIs often feel fear of stigma to seeking care for their STIs in health facilities where they are familiar with health care providers. The possible reason for this could be fear of the provider's judgment and stigma as well as social embarrassments as previously suggested by studies from the USA and Ethiopia. ${ }^{17,36}$

Perceived severity of STI was also one of the predictor factors for early health care-seeking behavior. This is also in line with other studies that reported the association of 
perceived severity with health-seeking behavior. ${ }^{24,37}$ The reason might be due to personal fear of the condition of illness and its complication. ${ }^{4}$ In contrast, some respondents may delay in seeking health care hoping that the disease will go away or believed that the disease is self-limiting.

Although this study found no relationship between delay in health care seeking and socio-demographic factors, some variables still provide a barrier to seek health care timely for STIs. For example, those with less advantaged socio-demographic characteristics such as women with low educational status and those residing in the rural experienced delay in health care seeking for STIs. ${ }^{38}$

\section{Limitation of the study}

It is noted that this study includes only patients who experienced STI symptoms and sought care at selected health facilities. However, as patients who did not seek care might have different characters generalizability should be done cautiously. Possible inaccuracy of self-report, married people may have more partners and not disclose this as concurrent relationships are more common/normative in some African subgroups including Ethiopia.

\section{Conclusion}

The delayed health care seeking among STI patients visiting health facilities in this study was high. Knowledge, behavior, and perception-related factors predict more for health-seeking behavior than socio-demographic characteristics. The findings highlight the need for interventions related to health education and promotion both at community and health facility level to improve awareness, change risk behavior, reduce stigma and avoid misconception to enhance early seeking and treatment. Further research is also needed to look if there is a link between late health care seeking and the high burden of HIV/AIDS in the study area.

\section{Compliance with Ethical Standards}

Ethical clearance was obtained from Mekelle University Research Ethics committee and Mekelle Zonal health office provided a support letter. Study participants verbally consented before data collection.

\section{Acknowledgment}

We would like to acknowledge the Mekelle University Department of Public health, Gambella Regional Health Bureau, all the data collectors and patients participated in this study.

\section{Disclosure}

The authors declare that they have no competing interests in this work.

\section{References}

1. World Health Organisation. Global Health Sector Strategy on Sexually Transmitted Diseases; Geneva:WHO, 2016

2. World Health Organisation. Factsheet on Sexually Transmitted Diseases; Geneva:WHO, 2016

3. WHO. Global Report on Sexually Transmitted Diseases; Geneva:WHO, 2015

4. Helene V, Hilda O, Judith K, et al. Gender differences in healthcareseeking behaviour for sexually transmitted diseases: a population-based study in Nairobi, Kenya. Sex Transm Infect. 2004;31(5):265-272.

5. Adhikari D, Prasad D. Factors affecting health seeeking behavior of senior citizens of Dharan. J Nobel Med Coll. 2014;3(1):50-57. doi:10.3126/jonmc.v3i1.10055

6. Bourne PA. Socio-demographic determinants of healthcare-seeking behaviour, selfreported illness and self-evaluated health status in Jamaica. Int J Collab Res Internal Med Publ Health. 2009;1(4):101-130.

7. Xu G, Xu J-H, Lu X-N, Yang L-J, Hu X-Y, Shi R. Influencing factors and characteristics of improper health seeking behaviors among sexually transmitted diseases outpatients. Fudan Univ J Med Sci. 2014;41:66-73.

8. Togoobaatar G, Ikeda N, Ali M, et al. Survey of non-prescribed use of antibiotics for children in an urban community in Mongolia. Bull World Health Organ. 2010;88:930-936. doi:10.2471/BLT.10.079004

9. Federal Ministry of Health (FMOH). Syndromic Managment of Sexually Transmited Infections; Addis Ababa, Ethiopia, 2015.

10. Balfe M, Brugha R, O' Donovan D, O' Connell E, Vaughan D. Triggers of self-conscious emotions in the sexually transmitted infection testing process. BMC Res Notes. 2010;17(3):229. doi:10.1186/ 1756-0500-3-229

11. Nyalela M, Dlungwane T, Taylor M, Nkwanyana N. Health seeking and sexual behaviour of men presenting with sexually transmitted infections in two primary healthcare clinics in Durban. South Afr J Infect Dis. 2018:1-6. doi:10.1080/23120053.2018.1520480

12. Phrasisombath K, Thomsen S, Sychareun V. Care seeking behaviour and barriers to accessing services for sexually transmitted infections among female sex workers in Laos. BMC Health Serv Res. 2012;12:37. doi:10.1186/1472-6963-12-37

13. Agambire R, Clerk C. Healthcare seeking and sexual behaviour of clients attending the suntreso STI clinic. J Biol Agric Healthc. 2013;3 (10): $92-100$

14. Nagaddya G, Musinguzi B, Tumuhe JL. Determinants of health seeking behaviour among men in Luwero District. $J$ Educ Res Behav Sci. 2015;4(2):37-54.

15. Cherie A, Berhane Y. Knowledge of sexually transmitted infections and barriers to seeking health services among high school adolescents in Addis Ababa, Ethiopia. $J$ AIDS Clinic Res. 2012;3:153. doi:10.4172/2155-6113

16. Amin R, Shah NM, Becker S. Socioeconomic factors differentiating maternal and child health seekingbehavior in rural Bangladesh: a cross-sectional analysis. Int $J$ Equity Health.

17. Glanz, K., Rimer, B. K., \& Viswanath, K. (Eds.) Health behavior and health education: Theory, research, and practice (4th ed.). San Francisco, CA, US: Jossey-Bass, 2008..

18. Arnault DS. Cultural determinants of help seeking: a model for research and practice. Res Theory Nurs Pract. 2009;23(4):259-278.

19. Govender I, Eche M. Health seekingbehaviour of people with sexually transmitted infections in the community of Nkomazi East, Mpumalanga. South Afr J Epidemiol Infect. 2012;27(4):195-198. doi:10.1080/10158782.2012.11441508 
20. Langeni T. Contextual factors associated with treatment-seeking and higher-risk sexual behaviour in Botswana among men with symptoms of sexually transmitted infections. Afr J AIDS Res. 2007;6(3):261269. doi: $10.2989 / 16085900709490422$

21. Newton-Levinson A, Leichliter JS, Chandra-Mouli V. Help and care seeking for sexually transmitted infections among youth in low- and middle-income countries. Sex Transm Dis. 2017;44(6):319-328. doi:10.1097/OLQ.0000000000000607

22. Ribera JM, Hausmann-Muela S. The straw that breaks the camel's back. Redirecting health seekingbehavior studies on malaria and vulnerability. Med Anthropol Q. 2011;25(1):103-121.

23. Mercer CH, Sutcliffe L, Johnson AM, et al. How much do delayed healthcare seeking, delayed care provision, and diversion from primary care contribute to the transmission of STIs? Sex Transm Infect. 2007;83(5):400-405. doi:10.1136/sti.2006.024554

24. Begashaw B, Tessema F, Gesesew HA. Healthcare seeking behavior in SouthwesT Ethiopia. PLoS One. 2015;11(9):e20624.

25. Khan A, Fortenberry JD, Temkit MH, Tu W, Orr DP, Batteiger BE. Gender differences in sexual behaviours in response to genitourinary symptoms Sex Transm Infect. 2005;81(3):262-266. doi:10.1136/sti.2004.010587

26. Thi Thu H, Ziersch A, Hart G. Healthcare-seeking behaviours for sexually transmitted infections among women attending the national institute of dermatology and venereology in Vietnam. Sex Transm Infect. 2007;83(5):406-410. doi:10.1136/sti.2006.022079

27. Cherie A, Berhanu Y. Knowledge of sexually transmitted infections and barriers to seeking health services among high school adolescents in Addis Ababa, Ethiopia. J AIDS Clinic Res. 2012;3:153.

28. Lubega GN, Musinguzi B, Tumuhe JL. Determinants of health seeking behaviour among men in Luwero District. J Educ Res Behav Sci. 2015;4(2):37-54

29. Alli F, Maharaj P. Interpersonal relations between healthcare workers and young clients: barriers to accessing sexual and reproductive healthcare among university students in South Africa. J Community Health. 2013;38 (1):150-155.
30. World Health Organisation. Global Health Sector Strategy on Sexually Transmitted Disease; Geneva: WHO; 2016.

31. Leichliter JS, Paz-Bailey G, Friedman LA. Clinics aren't meant for men: sexual healthcare access and seeking behaviours among men in Gauteng province, South Africa. Soc Asp HIV/AIDS. 2011;8(2):8288. doi:10.1080/17290376.2011.9724989

32. Stephenson R. Community-level gender equity and extramarital sexual risk-taking among married men in eight African countries. Int Perspect Sex Reprod Health. 2010;36:178-188. doi:10.1363/3617810

33. Molla M, Berhane Y, Emmelin M, Lindtjørn AB. Readiness of youth in rural Ethiopia to seek health services for sexually transmitted infections. Afr J AIDS Res. 2009;8(2):135-146. doi:10.2989/ AJAR.2009.8.2.2.854

34. Shiferaw Y, Alemu A, Girma A, et al. Assessment of knowledge, attitude and risk behaviors towards HIV/AIDS and other sexual transmitted infection among preparatory students of Gondar town, north west Ethiopia. BMC Res Notes. 2011;4:505. doi:10.1186/17560500-4-505

35. Koye M, Feleke A, Mengesha ZB. Reproductive health service utilization and associated factors in Gondar town, North Ethiopia. BMC Health Serv Res. 2013;13:294. doi:10.1186/ 1472-6963-13-438

36. Central Statistical Agency [Ethiopia] and ICF International. Ethiopia Demographic and Health Survey. Addis Ababa, Ethiopia and Calverton, MD, USA: Central Publishing House Statistical Agency and ICF International; 2011.

37. Leval A, Sundström K, Ploner A, Dahlström LA, Widmark C, Sparén P. Assessing perceived risk and STI prevention behavior: a national population-based study with special reference to HPV. PLoS One. 2011;6(6):e20624. doi:10.1371/journal.pone.0020624

38. Thu H, Ziersch A, Hart G. Healthcare-seeking behaviours for sexually transmitted infections among women attending the National Institute of Dermatology and venereology in Vietnam. Sex Transm Infect. 2007;83:406-410. doi:10.1136/sti.2006.022079
HIV/AIDS - Research and Palliative Care

\section{Publish your work in this journal}

HIV/AIDS - Research and Palliative Care is an international, peerreviewed open-access journal focusing on advances in research in HIV, its clinical progression and management options including antiviral treatment, palliative care and public healthcare policies to control viral spread. The manuscript management system is completely online and includes a very quick and fair peer-review system, which is all easy to use. Visit http://www.dovepress.com/testimonials.php to read real quotes from published authors. 